\title{
O USO DA MADEIRA NAS REDUÇÕES \\ JESUÍTICO-GUARANI DO RIO GRANDE DO SUL. \\ 12 - ANÁLISE CRÍTICA ${ }^{1}$
}

\section{MARIA CRISTINA SCHULZE-HOFER ${ }^{2}$ JOSÉ NEWTON CARDOSO MARCHIORI ${ }^{3}$}

\section{RESUMO}

O uso da madeira nas reduções Jesuítico-Guarani do Rio Grande do Sul é analisado com base em 10 amostras, constantes de publicações anteriores. Destas, cinco amostras são de ipê-roxo (Handroanthus heptaphyllus), três de cedro (Cedrela fissilis), uma de ipê-amarelo (Handroanthus phlcherrimus) e outra de pinheiro-do-Paraná (Araucaria angustifolia). O estudo, incluindo amostras de esculturas religiosas e peças construtivas, demonstra um conhecimento surpreendente acerca do material utilizado, por terem sido escolhidas as melhores madeiras disponíveis na região, para os distintos usos.

Palavras-chave: Missões Jesuíticas, Anatomia da Madeira, Rio Grande do Sul.

\section{SUMMARY}

[Wood utilization in the Jesuitic-Guarani Missions from Rio Grande do Sul state, Brazil. 12 - Critical analysis].

The utilization of wood in the Jesuitic-Guarani Missions from Rio Grande do Sul state (Brazil) is examined based on ten samples, previously published. Five of these species were identified as Handroanthus heptaphyllus (Purple ipê), three as Cedrela fissilis (spanish cedar), one as Handroanthus pulcherrimus (Yellow ipê) and another one as Araucaria angustifolia (Parana pine). The study, including samples from sacred sculptures and structural pieces, reveals a surprisingly knowledge about the raw material, due the selection of the best woods for distinct uses.

Key words: Jesuitic Missions, wood anatomy, Rio Grande do Sul state.

\section{INTRODUÇÃO}

A literatura sobre as Missões JesuíticoGuarani do Rio Grande do Sul dispõe de escassas informações sobre a identidade das madeiras utilizadas em construções e peças artísticas.

Em publicações anteriores, foram anatomicamente identificadas 10 amostras de madeira, que constituem o substrato do presente estudo sobre o uso desta matéria-prima nos Sete Povos.

1 Recebido em 27-X-2009 e aceito para publicação em 13-I-2010.

2 Arquiteta, Dra. IPHAN - Instituto do Patrimônio Histórico e Artístico Nacional. Schulze-hofer@gmx.de

3 Engenheiro Florestal, Dr., bolsista de Produtividade em Pesquisa (CNPq - Brasil). Professor Titular do Departamento de Ciências Florestais, Universidade Federal de Santa Maria, Santa Maria, RS. marchiori@pq.cnpq.com.br

\section{ANÁLISE CRÍTICA}

O exame anatômico de 10 amostras de madeira procedentes das Reduções JesuíticoGuarani do Rio Grande do Sul comprova o uso efetivo do ipê-roxo (Handroanthus heptaphyllus (Vell.) Mattos), do cedro (Cedrela fissilis Vell.), do ipê-amarelo (Handroanthus pulcherrimus (Sandwith) S. Grose) e do pinheiro-brasileiro (Araucaria angustifolia (Bert.) Kuntze). Longe de esgotar o tema - e apesar da limitação amostral -, os resultados obtidos trazem importantes novidades sobe o uso da madeira nas antigas Missões.

A lista das espécies utilizadas nos Sete Povos não se restringe, certamente, às 4 acima nominadas. Documentos da época, como visto em artigo anterior (Marchiori \& Schulze-Hofer, 2008), apontam para o emprego do louro (Cordia trichotoma Vell.) Arráb. ex Steud.), da 
cabriúva (Myrocarpus frondosus Allem.), do pau-ferro (Myracrodruon balansae (Engl.) Santin), da tajuva (Maclura tinctoria (L.) Don ex Steud.), da timbaúva (Enterolobium contortisiliquum (Vell.) Morong), do alecrim (Holocalyx balansae Micheli) e das canelas, termo, este, aplicado a diversas espécies (e gêneros) da família Lauraceae.

Outras madeiras, conhecidas tão somente pelos nomes em guarani (Aqui, Anguay, Iruquipitangy e Isangy), ainda aguardam pela identificação dos respectivos binômios latinos, ponto de partida para qualquer abordagem cientificamente embasada. De todo modo, o estado atual do conhecimento permite a formulação de algumas conclusões sobre o uso da madeira nas Reduções Jesuítico-Guarani no Rio Grande do Sul.

Em primeiro lugar, chama atenção, nos elementos arquitetônicos, a escolha adequada do ipê-roxo (Handroanthus impetiginosus) para vergas, pilares e demais usos que requerem resistência físico-mecânica e durabilidade natural. O uso desta madeira foi anatomicamente comprovado em cinco das amostras investigadas: na verga da porta da frontaria da Igreja de São Miguel Arcanjo (Schulze-Hofer \& Marchiori, 2008); no pilar do átrio da Igreja de São Lourenço (Marchiori \& Schulze-Hofer, 2009); na mísula do alpendre do Colégio de São Luiz Gonzaga (Schulze-Hofer \& Marchiori, 2009); na viga do coro da Igreja de São Miguel Arcanjo (Marchiori \& Schulze-Hofer, 2009); e na verga da porta da sacristia nova (lado evangelho) da Igreja de São Miguel Arcanjo (Schulze-Hofer \& Marchiori, 2009). A comprovação do uso desta espécie em metade das amostras examinadas pode dever-se, tão somente, à notável durabilidade natural da madeira, famosa por sua resistência à biodeterioração, mesmo quando submetida à intempérie, em longo tempo de exposição.

É bastante provável, todavia, que outras espécies tenham servido para os mesmos fins do ipê-roxo nas construções jesuíticas; a ausência de registro no material investigado, neste caso, poderia ser atribuído à biodeterioração, contingência previsível em madeiras de menor durabilidade natural.

De todo modo, cabe salientar a escolha acertada, feita pelos arquitetos e construtores missioneiros, posto que não poderia haver seleção mais criteriosa na flora regional, com a possível exceção do pau-ferro (Myracrodruon balansae (Engl.) Santin) e do inhanduvá (Prosopis affinis Spreng), espécies igualmente conhecidas e valorizadas na época, segundo relatos de antigos cronistas. ${ }^{4}$

A respeito das duas últimas, cabe observar que elas não ocorrem naturalmente nas proximidades de São Miguel Arcanjo, São Lourenço e São Luiz Gonzaga, as três reduções envolvidas nos estudos anatômicos realizados. Pelo critério de proximidade fitogeográfica - aspecto de grande importância ao tempo dos Jesuítas, pela dificuldade de transporte -, é de se esperar que o pau-ferro (Myracrodruon balansae) tenha servido para os mesmos fins, pelo menos em parte, nas reduções de São Nicolau e São Borja, e o inhanduvá (Prosopis affinis) na de Japejú, em território argentino.

Árvore de grande porte, com troncos retos e de diâmetro considerável em indivíduos adultos, o ipê-roxo produz madeira de notável durabilidade natural, sobretudo a insetos xilófagos. Arquitetos experientes e bons observadores, os jesuítas responsáveis pelas construções souberam escolher o melhor que a natureza podia oferecer na região, valendo-se, inclusive, de técnicas primitivas de preservação, mas com efeitos positivos para a durabilidade da madeira. É o caso o uso do chamuscamento ou queima con-

\footnotetext{
Além destas espécies, a literatura jesuítica refere o uso das seguintes madeiras: apiterebi ou peterebi, o louropardo (Cordia trichotoma (Vell.) Arráb. ex Steud); anguay, anguaí, ivirá-payó, ivirapayé ou iviraisi, a atual cabreúva (Myrocarpus frondosus Allem.); querandi ou kirandi, o jasmim-grado do Alto Uruguai (Rauvolfia sellowii Müll. Arg.); tatayba ou tatáyba, a tajuva (Maclura tinctoria (L.) Don ex Steud.); e ybirapepé, yvirá-pepé ou ybirá-pepé, o alecrim-do-mato (Holocalyx balansae Micheli), entre outras.
} 
trolada da base dos pilares, na parte a ser enterrada, de acordo com relato do Padre José Cardiel. ${ }^{5}$ Numa época e meio tão limitados no que diz respeito a instrumentos e técnicas de trabalho, a carbonização dos tecidos externos pode ser interpretada como método inteligente de preservação, posto que, sem comprometer a resistência, dificulta o acesso dos biodecompositores do solo ao interior da madeira, com reflexos positivos na vida útil da peça. Muito elucidativo, igualmente, é o relato do método de trabalho posterior de aparelhamento, na parte visível dos pilares, até alcançar a forma definitiva de coluna, com seu pedestal e cornija.

O uso preferencial do ipê-roxo (Handroanthus heptaphyllus (Vell.) J. Mattos), em relação ao ipê-amarelo (Handroanthus pulcherrimus (Sandw.) S. Grose), manifestada, presumivelmente, pela identificação de cinco amostras da primeira espécie (verga da porta da frontaria da Igreja de São Miguel Arcanjo, viga do coro da Igreja de São Miguel Arcanjo, verga da porta da sacristia nova da Igreja de São Miguel Arcanjo, mísula do alpendre do colégio de São Luiz Gonzaga, pilar do átrio da Igreja de São Lourenço) e apenas uma da segunda (Pilar do Colégio de São Miguel Arcanjo), também demonstra acerto de escolha, posto que o ipêroxo supera o amarelo sob quaisquer pontos de vista, sejam dendrológicos ou anatômico-

\footnotetext{
5 Sobre o tema, o Padre José Cardiel informa que as toras, "con mucha parte de sus raíces" eram trazidas ao povo com ajuda de 20 a 30 juntas de bois, devido ao grande comprimento e peso das mesmas. A parte da tora a ser enterrada (base do tronco, com parte das raízes), era muito bem chamuscada com fogo, "para que resistan muy bien a la humedad", antes da parte visível do pilar ser trabalhada para ficar na forma definitiva de coluna (seção quadrada ou circular), com seu pedestal e cornija. Concluída essa etapa, o pilar era colocado na posição definitiva, dentro do buraco (hoyo) previamente aberto, sendo a base alicerçada por grandes pedras e o restante preenchido por tijolos quebrados, depois pedras e finalmente com terra bem compactada, cuidando-se para nivelar o pilar (Cardiel, 1989, p. 59).
}

tecnológicos. Comparado à espécie afim, o ipêroxo produz indivíduos de maior fuste e troncos de maior diâmetro, aspectos vantajosos para uso em vigas e pilares, por exemplo. Além disso, a madeira do ipê-roxo apresenta menor percentagem de parênquima axial e fibras de paredes mais espessas e lignificadas, com reflexos positivos na resistência físico-mecânica e durabilidade natural.

Com relação ao cedro (Cedrela fissilis (Vell.) Arráb. ex Steud.), cabe salientar que não existe na flora regional madeira mais dócil para esculturas e obras de talha, aliada à resistência aos agentes decompositores (durabilidade natural) e bom acabamento. De odor agradável, a madeira também aceita pigmentos com facilidade, aspecto importante em obras religiosas (policromia).

Da imaginária investigada, o uso do cedro foi anatomicamente comprovado nas esculturas de São Lourenço Mártir (Marchiori \& SchulzeHofer, 2009), Santo Estanislau Kostka (Marchiori \& Schulze-Hofer, 2010) e Nossa Senhora das Dores (Schulze-Hofer \& Marchiori, 2010), ao passo que o pinheiro brasileiro (Araucaria angustifolia (Bert.) Kuntze) foi identificado em apenas uma amostra, extraída da imagem de São José (Marchiori \& SchulzeHofer, 2009). Também nesta proporção (3 amostras de Cedrela fissilis e 1 de Araucaria angustifolia) fica demonstrado acerto de escolha, posto que o cedro é superior ao pinheirobrasileiro para fins de escultura.

Acerca deste ponto, cabe ponderar que os Jesuítas, por sua formação européia, estavam habituados a trabalhar com madeiras de coníferas, notadamente dos gêneros Pinus e Picea, e que eles souberam identificar a araucária como pinheiro. É muito provável, portanto, que o uso generalizado do cedro na imaginária missioneira possa dever-se à presença mais abundante da espécie nos fragmentos florestais da região, ao contrário da araucária, fato mais relevante na época do que na atualidade, pela dificuldade do transporte em grandes distâncias. Os padres, aliás, não pouparam elogios à madeira de 
araucária, notadamente pelo "verniz" (resina) contido em seus traqueóides longitudinais. ${ }^{6}$

No aprendizado com a flora euxilófora americana, os Jesuítas partiram de conhecimentos limitados, hauridos de experiências anteriores com madeiras européias. No tocante ao uso deste recurso florestal, a vivência com os índios foi, certamente, de proveito limitado, comparado aos setores alimentício e de medicamentos. Salvo raras exceções, os índios não costumavam ver a madeira como o fazemos atualmente, como importante matéria prima para fins industriais variados, até mesmo por desconhecerem instrumentos e técnicas adequadas de desdobro. Os nomes por eles atribuídos a espécies valiosas, como o cedro e o ipê-roxo, corroboram esta assertiva, posto que aludem mais à casca ou a características organolépticas da madeira, do que a propriedades da mesma ou a usos não tradicionais.

Pelos guaranis, o cedro era chamado de yaporá-izí, termo que alude à madeira de agradável fragrância, ou de igary, referência à indicação da madeira para a construção de canoas monóxilas, ditas igaras (Torres, 1970).

O ipê, por sua vez, era chamado de peropa ou i'pe'roua, com o significado de "casca" (Montoya, 1876) e "casca" (i'pe) "amarga" ('roua), respectivamente. Dentre a rica sinonímia popular, a palavra piúva, ainda hoje aplicada aos ipês em partes do Brasil, também deriva do guarani - i'pe'iua -, informando que se trata de planta (iua) ou árvore de casca (i'pe) peculiar.

O uso da madeira nas Reduções JesuíticoGuarani do Rio Grande do Sul demonstra admirável conhecimento e domínio deste recurso florestal, por parte de seus construtores e artífi-

\footnotetext{
${ }^{6}$ Sobre o efeito dos nós na madeira de araucária, o padre Diego de Boroa disse que "Las ramas que se van desgajando dejan todo el tronco como tachonado con arte, de unos nudos tersos y duros de color encendido que despues labrados al torno compiten com el Indiano marfil en resplandor y lisura (Boroa, 1990, p. 178).
}

ces. O mesmo assombro que perpassa ao examinar-se a complexidade da obra e o alto nível artístico alcançado nas Missões, pode ser reconhecido quando se aprofunda na investigação do uso da madeira, campo recém desbravado, ainda à espera de substanciosa pesquisa.

\section{REFERÊNCIAS BIBLIOGRÁFICAS}

BOROA, D. de. Cartas Anuas de la província jesuítica del Paraguay: 1632 a 1634. Buenos Aires: Academia Nacional de la Historia, 1990. 335 p.

CARDIEL, L. Las Misiones del Paraguay. Madrid: Historia 16, 1989. 204 p.

MARCHIORI, J.N.C.; SCHULZE-HOFER, M.C. O uso da madeira nas Reduções Jesuítico-Guarani do Rio Grande do Sul. 1 - Vegetação regional e subsídios florísticos. Balduinia, Santa Maria, n. 14, p. 1-18, 2008.

MARCHIORI, J.N.C.; SCHULZE-HOFER, M.C. O uso da madeira nas Reduções Jesuítico-Guarani do Rio Grande do Sul. 3 - Imagem de São José. Balduinia, Santa Maria, n. 15, p. 1-4, 2009a.

MARCHIORI, J.N.C.; SCHULZE-HOFER, M.C. O uso da madeira nas Reduções Jesuítico-Guarani do Rio Grande do Sul. 5. Fragmento de madeira procedente de escavações arqueológicas no átrio da Igreja de São Lourenço. Balduinia, Santa Maria, n. 16, p. 1-5, 2009 b.

MARCHIORI, J.N.C.; SCHULZE-HOFER, M.C. O uso da madeira nas Reduções Jesuítico-Guarani do Rio Grande do Sul. 6 - Imagem de São Lourenço Mártir. Balduinia, Santa Maria, n. 17, p. 7-10, 2009c.

MARCHIORI, J.N.C.; SCHULZE-HOFER, M.C, O uso da madeira nas Reduções Jesuítico-Guarani do Rio Grande do Sul. 7 - Viga do coro da Igreja de São Miguel Arcanjo. Balduinia, Santa Maria, n. 17, p. 29-33, 2009d.

MARCHIORI, J.N.C.; SCHULZE-HOFER, M.C. O uso da madeira nas Reduções Jesuítico-Guarani do Rio Grande do Sul. 9 - Pilar do Colégio de São Miguel Arcanjo. Balduinia, Santa Maria, n. 20, p. 5-9, 2010a.

MARCHIORI, J.N.C.; SCHULZE-HOFER, M.C. O uso da madeira nas Reduções Jesuítico-Guarani do Rio Grande do Sul. 10 - Imagem de Santo Estanislau Kostka. Balduinia, Santa Maria, n. 21, p. 29-32, 2010b. 
MONTOYA, A.R. de. Vocabulário y tesoro de la lengua guarani (ó mas bien tupi). Viena: Faesy y Frick; Paris: Maisonnneuve y Cia, 1876. 510 p.

SCHULZE-HOFER, M.C.; MARCHIORI, J.N.C. O uso da madeira nas Reduções Jesuítico-Guarani do Rio Grande do Sul. 2 - Verga da frontaria da Igreja de São Miguel Arcanjo. Balduinia, Santa Maria, n. 14, p. 29-32, 2008.

SCHULZE-HOFER, M.C.; MARCHIORI, J.N.C. O uso da madeira nas Reduções Jesuítico-Guarani do Rio Grande do Sul. 4 - Verga da porta da sacristia nova (lado evangelho) da Igreja de São Miguel Arcanjo. Balduinia, Santa Maria, n. 15, p. 24-27, 2009a.
SCHULZE-HOFER, M.C.; MARCHIORI, J.N.C. O uso da madeira nas Reduções Jesuítico-Guarani do Rio Grande do Sul. 8 - Mísula do alpendre do Colégio de São Luiz Gonzaga. Balduinia, Santa Maria, n. 19, p. 14-18, 2009 b.

SCHULZE-HOFER, M.C.; MARCHIORI, J.N.C. O uso da madeira nas Reduções Jesuítico-Guarani do Rio Grande do Sul. 11 - Imagem de Nossa Senhora das Dores. Balduinia, Santa Maria, n. 22, p. 31-34, 2010.

TORRES, D.M.G. Catálogo de plantas medicinales (y alimentícias y utiles) usadas en Paraguay. Asunción, 1970. 456 p. 